\title{
Alcohol intoxication and lack of helmet use are common in electric scooter-related traumatic brain injuries: a consecutive patient series from a tertiary university hospital
}

\author{
Eetu N. Suominen ${ }^{4}$. Antti J. Sajanti ${ }^{2}$. Eero A. Silver ${ }^{3} \cdot$ Veerakaisa Koivunen $^{1} \cdot$ Anton S. Bondfolk $^{1}$. \\ Janne Koskimäki ${ }^{2} \cdot$ Antti J. Saarinen ${ }^{4,5}$ (D)
}

Received: 18 November 2021 / Accepted: 19 December 2021 / Published online: 14 January 2022

(c) The Author(s) 2022

\begin{abstract}
Purpose Clinicians have increasingly encountered traumatic brain injuries (TBI) related to electric scooter (ES) accidents. In this study, we aim to identify the modifiable risk factors for ES-related TBIs.

Methods A retrospective cohort of consecutive patients treated for ES-related traumatic brain injuries in a tertiary university hospital between May 2019 and September 2021 was identified and employed for the study. The characteristics of the accidents along with the clinical and imaging findings of the injuries were collected from the patient charts.

Results During the study period, 104 TBIs related to ES accidents were identified. There was a high occurrence of accidents late at night and on Saturdays. In four cases, the patient's helmet use was mentioned (3.8\%). Seventy-four patients (71\%) were intoxicated. At the scene of the accident, seventy-seven (74\%) of the patients had a Glasgow Coma Scale score of 13-15, three patients (3\%) had a score of 9-12, and two patients (2\%) had a score of 3-8. The majority (83\%) of TBIs were diagnosed as concussions. Eighteen patients had evidence of intracranial injuries in the imagining. Two patients required neurosurgical procedures. The estimated population standardized incidence increased from 7.0/100,000 (95\% CI 3.5-11/100,000) in 2019 to $27 / 100,000$ (95\% CI 20-34/100,000) in 2021.

Conclusions Alcohol intoxication and the lack of a helmet were common in TBIs caused by ES accidents. Most of the accidents occurred late at night. Targeting these modifiable factors could decrease the incidence of ES-related TBIs.
\end{abstract}

Keywords Traumatic brain injury $\cdot$ TBI $\cdot$ Electric scooter $\cdot$ Brain trauma $\cdot$ Traffic accident

This article is part of the Topical Collection on Brain trauma

Antti J. Saarinen

antti.j.saarinen@utu.fi

1 Department of Clinical Medicine, University of Turku, Turku, Finland

2 Neurocenter, Department of Neurosurgery, Turku University Hospital and University of Turku, Turku, Finland

3 Department of Anaesthesia and Intensive Care, University of Turku and Turku University Hospital, Turku, Finland

4 Department of Paediatric Orthopaedic Surgery, University of Turku and Turku University Hospital, Kiinamyllynkatu 4-8, 20521 Turku, Finland

5 Department of Orthopaedics and Traumatology, University of Helsinki and Helsinki University Hospital, Helsinki, Finland

$\begin{array}{ll}\text { Abbreviations } \\ \text { CT } & \text { Computer tomography } \\ \text { EASR } & \text { European age-standardized rates } \\ \text { ED } & \text { Emergency department } \\ \text { ES } & \text { Electric scooter } \\ \text { ESP } & \text { European Standard Population } \\ \text { GCS } & \text { Glasgow Coma Scale } \\ \text { MRI } & \text { Magnetic resonance imaging } \\ \text { TBI } & \text { Traumatic brain injury }\end{array}$

\section{Introduction}

At the end of 2017, rental electric scooters (ESs) were first introduced into the USA as a new, nationwide means of transport. Recently, they have become a significant means of transportation for urban residents and have assumed a substantial portion of the micro-mobility market in cities worldwide. 
Since the introduction of rentable ESs in Finland, there have been frequent reports of accidents in the media and a widespread debate over the legislation on ES usage. In our city, ESs have been available for rent since the beginning of May 2019. In Finland, the maximum speed of ESs is limited to $25 \mathrm{~km}$ per hour. In the middle of July 2021, the maximum speed was lowered to $15 \mathrm{~km} /$ hour during the night at weekends (Fri-Sun, from 23:00 to 05:00). By jurisdiction, ESs are treated in a similar way to bicycles concerning helmet use and intoxication. Helmets are required by law but not enforced. Driving under the influence of alcohol is forbidden but not strictly enforced unless the driver causes evident danger to the public.

The findings of a recent review suggest frequent injuries to the head and extremities in ES-related accidents [30]. The reported occurrence of head injuries has varied between 15 and $40 \%$ of all ES-related injuries [16, 31]. Since ESs have only recently been introduced to the public, up-to-date data on injury patterns of ES-related TBIs are sparse. As their national and worldwide popularity increases, it is critical to provide better evidence on the injury patterns and severity of ES-related brain traumas. This information enables estimating the burden these injuries pose to the emergency departments and the health care system. Understanding the risk factors associated with injuries may better inform public decisions, affect individual safety, and guide future policy.

In this study, we describe the characteristics of ES-related traumatic brain injuries treated in a tertiary university hospital over a 2.5-year period. We also describe modifiable risk factors for electric scooter injuries. We hypothesized that the rate of helmet usage is low, the accidents occur mainly late at night, and that the accidents are frequently involved with alcohol intoxication.

\section{Patients and methods}

\section{Study design}

This study was conducted in the city of Turku, located in Southwest Finland. Approximately $20 \%$ of the population in Turku is aged between 20 and 29 years [19]. Turku is the only city located in the region of Southwest Finland in which rentable ESs are available. Patients requiring immediate or urgent specialized care in the city of Turku can seek treatment in Turku University Hospital which is a tertiary hospital covering a city population of 194,391 in 2020 . Our study center is the primary emergency department (ED) in the region, in which all traumatic injuries are treated. In 2020, a total of 1472 patients with TBIs were treated at our hospital. An institutional research board permit was obtained.

A retrospective cohort of consecutive patients was collected using patient charts from our center. We searched for patients diagnosed with intracranial injuries between 1st of May 2019 and 30th of September 2021 using International Classification of Diseases (ICD) codes S06.0-S06.9 and a keyword search for electrical scooters (electric scooter, E-scooter, etc.). After this, a keyword search without the ICD-codes was conducted for TBIs involving electrical scooters. This provided no additional patients. The involvement of an ES was then verified, and eligible patients were included in the study (Fig. 1). Patients with injuries related to non-electronic scooters, moped scooters, or other seated scooters were excluded. Follow-up visits for previous ESrelated injuries were excluded.

\section{Data collection}

The following data were collected: age, gender, time and date of the injury, helmet use, presence of primary unconsciousness, transportation by ambulance to the hospital, blood or breath alcohol level, Glasgow Coma Scale (GCS) score assessed at the scene of the accident or the emergency department (ED), possible other injuries sustained, the exact ICD-code, the type of radiological imaging, length of hospitalization, and interventions required for the TBI. Computed tomography (CT) and magnetic resonance imaging (MRI) scans were evaluated.

We classified the intracranial traumas according to the imaging findings: (1) loss of consciousness or concussion without CT or MRI findings (referred to as imaging negative), (2) CT or MRI diagnosed brain hemorrhages treated non-operatively (imaging positive), and (3) patients with CT and MRI diagnosed brain hemorrhages requiring operative treatment (imaging positive requiring operative treatment) [28]. The patients were also classified according to the Glasgow Coma Score addressed at the scene of the accident as follows: (1) mild TBI with GCS score 13-15, (2) moderate TBI with GCS score 9-12, and (3) severe TBI with GCS score $3-8$.

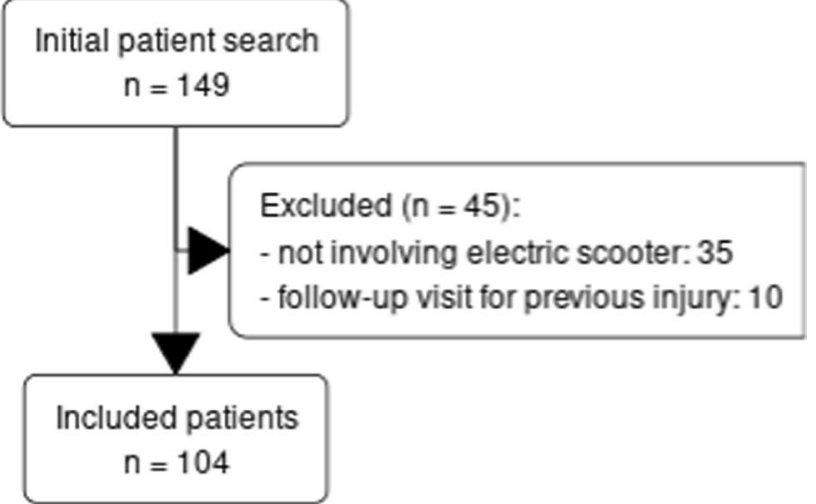

Fig. 1 Flowchart of the patient selection. Injuries related to other transportation methods than electric scooters and follow-up visits for previous injuries were excluded 


\section{Data analysis}

Analysis was conducted in R ( $\mathrm{R}$ 4.1.1, R Core Team, 2020). Descriptive analyses were reported as the means and SDs, medians and both quartiles and ranges, or absolute numbers and percentages referring to the study groups. Agestandardized rate allows comparison of incidences between different populations [6]. We calculated direct age- and sexstandardized incidence rates by multiplying the age-specific and age-sex-specific incidence rates with the corresponding age bracket weights of the European standard population (ESP) [6]. The 95\% confidence intervals for European agestandardized rates (EASR) were calculated using Poisson approximation [6].

\section{Results}

\section{Patient and event characteristics}

In total, 149 patients were identified, of whom after exclusion 104 were selected for the final analyses (Fig. 1). The demographic details of the patient population are presented in Table 1. There were 63 (61\%) males and 41 (39\%) females. The median age at the time of injury was 23.7 (range 5-71) years. Forty-nine percent of the patients were young adults, between the ages of 18 and 25 . The highest prevalence was $215 / 100,000$ in the age group of 20-25 years (264 in males and 174 in females, Table 2). The prevalence was higher in males (68 in males vs. 41 in females, Supplementary Tables I, II). The EASR during the whole study period was 44/100,000 (95\%CI 35-53/100,000, Table 2). EASRs were $57 / 100,000(95 \%$ CI $42-72 / 100,000)$ for males and 32/100,000 (95\% CI 21-42/100,000) for females during the study period. There was an increase in the EASR from $7.0 / 100,00$ in 2019 (95\%CI 3.5-11/100,000) to $27 / 100,000$ in 2021 (95\%CI 20-34/100,000, Supplementary Tables III, V). There was a peak of injuries late at night: $81 \%$ of the accidents occurred between 6 p.m. and 6 a.m. (Fig. 2). The occurrence was the highest during Saturdays (29.8\%) and Thursdays (19.2\%). The injuries were most common during the summer months: $82 \%$ of the accidents occurred between May and September (Fig. 3).

The majority of the patients (64\%) did not wear a helmet at the time of the accident and in only four cases was the patient's use of a helmet mentioned (3.8\%). No information concerning helmet usage was available for 33 patients $(32 \%)$. Ten cases involved riding the scooter with two persons onboard $(9.6 \%)$. Primary unconsciousness was reported in $33(32 \%)$ patients. GCS addressed at the scene of the accident was 13-15 for seventy-seven (74\%) patients, 9-12 for three (3\%) patients, and 3-8 for two (2\%) patients. In $22 \%$ of the cases, GCS was not reported. Seventy-four patients
Table 1 Patient characteristics

\begin{tabular}{|c|c|}
\hline \multicolumn{2}{|l|}{ Age, median (years), (Q1, Q3, range) } \\
\hline All & $24(20.5,30.1,5-70)$ \\
\hline Male & $24(21.1,32.8,8-55)$ \\
\hline Female & $22(20.3,26.8,5-70)$ \\
\hline \multicolumn{2}{|l|}{ Age group (years), n (\%) } \\
\hline$<18$ & $10(9.6)$ \\
\hline $18-25$ & $51(49.0)$ \\
\hline $25-40$ & $31(29.8)$ \\
\hline$>40$ & $12(11.5)$ \\
\hline \multicolumn{2}{|l|}{ Sex } \\
\hline Male & $63(60.6)$ \\
\hline Female & $41(39.4)$ \\
\hline \multicolumn{2}{|l|}{ Time of accident } \\
\hline Midnight to 6 a.m & $47(45.2)$ \\
\hline 6 a.m. to noon & $5(4.8)$ \\
\hline Noon to 6 p.m & $12(11.5)$ \\
\hline 6 p.m. to midnight & $37(35.6)$ \\
\hline Unknown & $3(2.9)$ \\
\hline \multicolumn{2}{|l|}{ Day of accident } \\
\hline Monday & $3(2.9)$ \\
\hline Tuesday & $12(11.5)$ \\
\hline Wednesday & $14(13.5)$ \\
\hline Thursday & $20(19.2)$ \\
\hline Friday & $13(12.5)$ \\
\hline Saturday & $31(29.8)$ \\
\hline Sunday & $11(10.6)$ \\
\hline \multicolumn{2}{|l|}{ Month of accident } \\
\hline January & $1(1.0)$ \\
\hline February & $0(0)$ \\
\hline March & $1(1.0)$ \\
\hline April & $4(3.8)$ \\
\hline May & $16(15.4)$ \\
\hline June & $15(14.4)$ \\
\hline July & $14(13.5)$ \\
\hline August & $22(21.2)$ \\
\hline September & $18(17.3)$ \\
\hline October & $7(6.7)$ \\
\hline November & $4(3.8)$ \\
\hline December & $2(1.9)$ \\
\hline \multicolumn{2}{|l|}{ Intoxication } \\
\hline No intoxication & $21(20.2)$ \\
\hline Alcohol reported & $74(71.2)$ \\
\hline$<0.5 \%$ & $1(1.4)$ \\
\hline $0.5-1.2 \%$ & $7(9.6)$ \\
\hline$>1.2 \%$ & $58(79.4)$ \\
\hline Alcohol reported but level unknown & $7(9.6)$ \\
\hline Unknown & $9(8.7)$ \\
\hline \multicolumn{2}{|l|}{ Helmet use } \\
\hline Yes & $4(3.8)$ \\
\hline No & 67 (64.4) \\
\hline
\end{tabular}


Table 1 (continued)

\begin{tabular}{ll}
\hline Age, median (years), (Q1, Q3, range) & \\
\hline All & $24(20.5,30.1,5-70)$ \\
\hline Unknown & $33(31.7)$ \\
Collision & \\
No & $96(92.3)$ \\
Car & $5(4.8)$ \\
E-scooter & $1(1.0)$ \\
Bicycle & $1(1.0)$ \\
Moped & $1(1.0)$
\end{tabular}

(71\%) were brought to ED by ambulance. Forty-nine patients were discharged directly from ED without head imaging or imaging findings. In patients requiring surveillance, 36 were discharged during the first $24 \mathrm{~h}$. Fourteen patients required surveillance for one to seven days (mean 2.0, range 1-). Three patients required longer surveillance and were discharged after seven, eight, and 14 days. None of the patients had ongoing antithrombotic medication.

In total, $74 \%$ of the patients were under the influence of alcohol. The mean alcohol level in breath or blood was $1.8 \%$ (range, 0.3-3.6) in intoxicated patients. Fifty-eight (77\%) intoxicated patients had alcohol concentrations higher than $1.2 \%$. As mentioned, $81 \%$ of the accidents occurred between 6 p.m. and 6 a.m. In these cases, $86 \%$ of the patient were under the influence of alcohol. In one patient, there was a report of cannabis use in addition to alcohol intoxication.
Ten patients had a cranial fracture, nine had a maxillofacial fracture, and three had both skull and maxillofacial fractures. Two patients required operative treatment for maxillofacial fractures. Other fractures involved scapula, proximal phalange, and rib fractures.

\section{Traumatic brain injuries (TBIs)}

A CT scan was performed on 80 patients and an MRI scan on two patients. Twenty-two patients $(21 \%)$ were clinically evaluated and required no imaging. Most injuries were diagnosed as concussions (86 cases, $82 \%$, Table 3 ). In patients with CT or MRI scans, 64 patients $(78 \%)$ had no traumatic intracranial findings. Eighteen patients had imaging positive intracranial injury (Table 4). Two of those patients required neurosurgical procedures. Imaging positive injuries were as follows: diffuse traumatic brain injury in three patients (3\%), brain contusion in seven patients (7\%), epidural hemorrhage in one patient (1\%), traumatic subdural hemorrhage in seven patients $(7 \%)$, and traumatic subarachnoid hemorrhage in seven patients $(7 \%)$. One patient required hematoma evacuation after which an intracranial pressure monitoring was installed. The patient remained under surveillance in the neurosurgical department for two days. Another patient required intracranial pressure monitoring and remained under surveillance for seven days. Eighty-nine percent of the imaging positive patients were under the influence of alcohol (mean alcohol level 1.8\%o.).
Table 2 European age standardized rates of all 321 ES-related TBIs in Turku 2019-2021

\begin{tabular}{lcclcc}
\hline Age & $\begin{array}{l}\text { European standard } \\
\text { population 2013 }\end{array}$ & $\begin{array}{l}\text { Population in } \\
\text { Turku }(2020)\end{array}$ & $\begin{array}{l}\text { ES- } \\
\text { related } \\
\text { TBIs }\end{array}$ & $\begin{array}{l}\text { Prevalence in the age } \\
\text { group per 100,000 }\end{array}$ & $\begin{array}{l}\text { European age stand- } \\
\text { ardized rate (EASR) }\end{array}$ \\
\hline $0-4$ & 5,500 & 8,014 & 0 & 0.0 & 0.0 \\
$5-9$ & 5,500 & 8,372 & 2 & 23.9 & 1.3 \\
$10-14$ & 5,500 & 8,052 & 7 & 86.9 & 4.8 \\
$15-19$ & 6,000 & 8,775 & 9 & 102.6 & 5.6 \\
$20-24$ & 6,000 & 19,995 & 43 & 215.1 & 12.9 \\
$25-29$ & 6,500 & 19,069 & 17 & 89.2 & 5.4 \\
$30-34$ & 7,000 & 15,181 & 9 & 59.3 & 3.9 \\
$35-39$ & 7,000 & 13,266 & 5 & 37.7 & 2.6 \\
$40-44$ & 7,000 & 11,419 & 1 & 8.8 & 0.6 \\
$45-49$ & 7,000 & 9,781 & 2 & 20.5 & 1.4 \\
$50-54$ & 6,500 & 10,578 & 7 & 66.2 & 0.6 \\
$55-59$ & 6,000 & 10,809 & 1 & 9.3 & 0.0 \\
$60-64$ & 5,500 & 10,435 & 0 & 0.0 & 0.0 \\
$65-69$ & 5,000 & 10,560 & 0 & 0.0 & 0.44 \\
$70-74$ & 9,000 & 11,317 & 1 & 8.8 & $\mathbf{4 4 . 2}$ \\
$75->90$ & 5,500 & 18,768 & 0 & 0.0 & \\
All ages & $\mathbf{1 0 0 , 0 0 0}$ & $\mathbf{1 9 4 , 3 9 1}$ & $\mathbf{1 0 4}$ & $\mathbf{5 3 . 5}$ & \\
\hline
\end{tabular}


Fig. 2 Daily prevalence and the time of the ES-related injuries. $\mathrm{NA}=$ Day known; exact time not available

Fig. 3 Monthly prevalence. The prevalence of ES-related TBIs increased towards the end of the study period and was lower in the winter months. Rentable ESs were generally not available during the snow cover
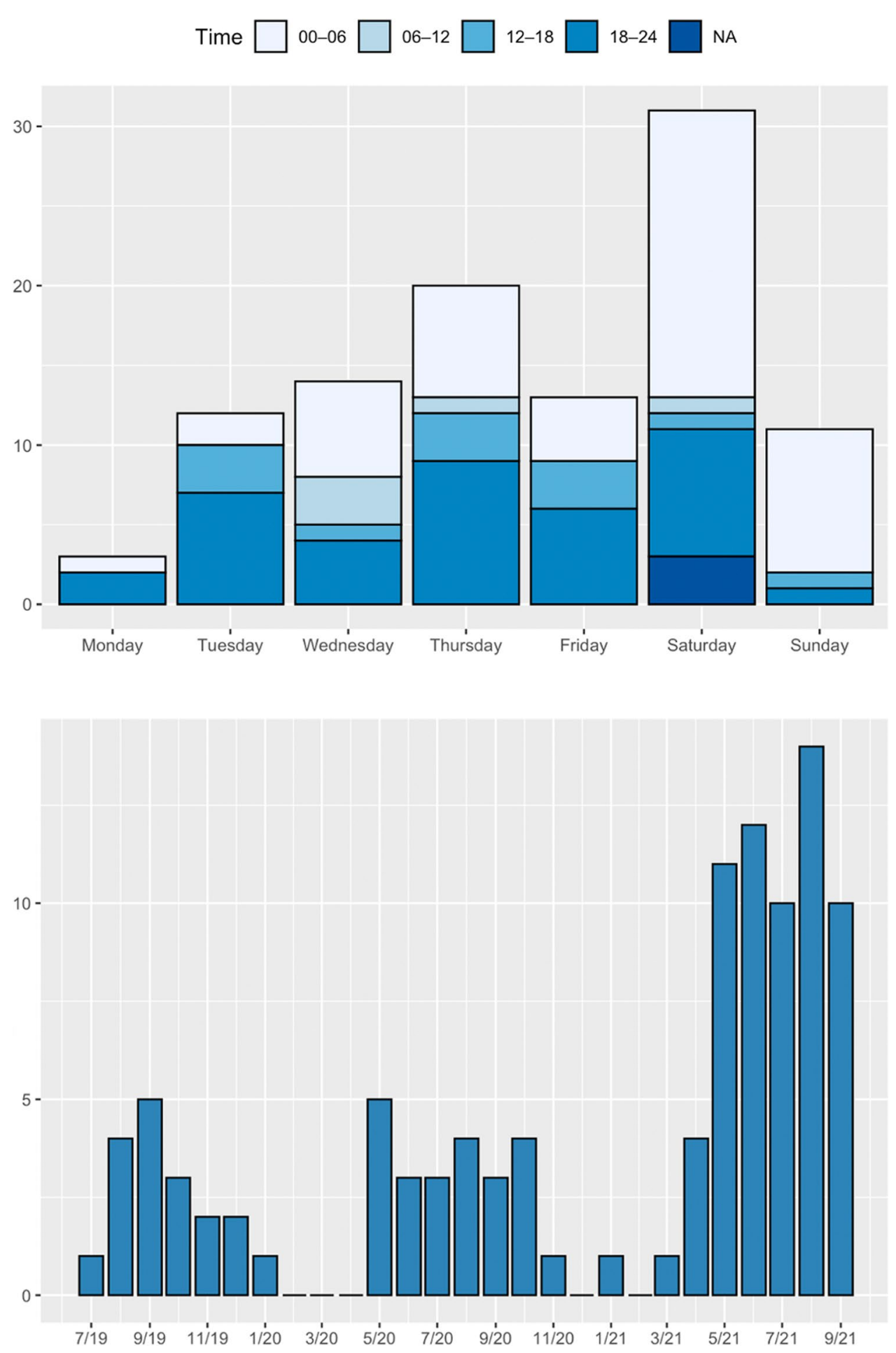

\section{Discussion}

The present study demonstrates an evident increase in the incidence of ES-related TBIs in our institute between 2019 and 2021. The accident patterns were as we hypothesized: high alcohol levels and lack of helmet use were prominently present in patients with ES-related TBIs. Moreover, most accidents occurred during the summer months and late at night.

Common ES-related injuries include head traumas, TBIs, and fractures [18]. Previous studies have reported a high incidence of head injuries and TBIs in ES accidents [11, 20, 26, 32]. Head traumas, half of which included TBI, were the 
Table 3 Injury characteristics

\begin{tabular}{|c|c|}
\hline & $n(\%)$ \\
\hline \multicolumn{2}{|l|}{ Transport to emergency department } \\
\hline Ambulance & $74(71.2)$ \\
\hline Ambulatory & $30(28.8)$ \\
\hline \multicolumn{2}{|l|}{ GCS score at the scene of the accident } \\
\hline $13-15$ & $77(74.0)$ \\
\hline $9-12$ & $3(2.9)$ \\
\hline $3-8$ & $2(1.9)$ \\
\hline Unknown & $22(21.2)$ \\
\hline \multicolumn{2}{|l|}{ Primary unconsciousness } \\
\hline Yes & $33(31.7)$ \\
\hline No & $54(51.9)$ \\
\hline Unknown & $17(16.3)$ \\
\hline \multicolumn{2}{|l|}{ Traumatic brain injuries (ICD-10) } \\
\hline Concussion (S06.0) & $86(82.7)$ \\
\hline Diffuse traumatic brain injury (S06.2) & $3(2.9)$ \\
\hline Brain contusion (S06.3) & $7(6.7)$ \\
\hline Epidural hemorrhage (S06.4) & $1(1.0)$ \\
\hline Traumatic subdural hemorrhage (S06.5) & $7(6.7)$ \\
\hline Traumatic subarachnoid hemorrhage (S06.6) & $7(6.7)$ \\
\hline \multicolumn{2}{|l|}{ Cranial fractures } \\
\hline Yes & $22(21.2)$ \\
\hline Cranial & $10(45.5)$ \\
\hline Maxillofacial & $9(40.9)$ \\
\hline Both & $3(13.6)$ \\
\hline No & $82(78.8)$ \\
\hline \multicolumn{2}{|l|}{ Other fractures } \\
\hline Yes & $3(2.9)$ \\
\hline Upper extremity & $2(66.6)$ \\
\hline Rib & $1(33.3)$ \\
\hline No & $101(97.1)$ \\
\hline \multicolumn{2}{|l|}{ Radiological imaging } \\
\hline Yes & $82(78.8)$ \\
\hline $\mathrm{CT}$ & $80(97.6)$ \\
\hline MRI & $2(2.4)$ \\
\hline No & $22(21.2)$ \\
\hline \multicolumn{2}{|l|}{ Imaging } \\
\hline Imaging negative & $64(78.0)$ \\
\hline Imaging positive & $16(19.5)$ \\
\hline Imaging positive requiring neurosurgical treatment & $2(2.4)$ \\
\hline \multicolumn{2}{|l|}{ Length of hospital stay } \\
\hline$<4 \mathrm{~h}$ & $49(47.1)$ \\
\hline $4-24 \mathrm{~h}$ & $38(36.5)$ \\
\hline 1-7 days & $14(13.5)$ \\
\hline$>7$ days & $3(2.9)$ \\
\hline
\end{tabular}

GCS, Glasgow Coma Scale

most common reason for ED visits for ES injuries in a study of 70,544 cases [7]. A recent case series described 13 severe injuries, which required neurosurgical intervention including skull fractures, central cord syndrome, and vertebral compression fractures related to ES injuries [23]. In that study, one patient was pronounced dead on arrival due to epidural hematoma resulting in midline shift and bilateral frontal subarachnoid hemorrhages [23]. In our study, eighteen patients had imaging positive injuries with two patients requiring neurosurgical procedures. Most patients in this study were under the age of 30 years. TBIs are a major cause of death and disability in the younger adult population [4, $12,14]$. Although the long-term effects were not assessed in our study, previous results show that young patients can be vulnerable to long-term difficulties due to a lack of coping skills [5]. Both upper and lower extremity fractures requiring operative treatment are reported in ES-related accidents [8, $24,29]$. In our cohort, the low incidence of upper extremity fractures may indicate that these patients may not have been able to react to the sudden fall or collision.

Although ES-related injuries make up only a minor portion of all ED visits for traumatic injuries, the increasing trend in the current study and previous studies is alarming $[7,9,17]$. A recent study showed a twofold increase in the incidence of E-scooter-related injuries in the USA between 2018 and 2019 [7]. According to a recent study, the incidence of ES-related injuries increased from 2.42 in 2017 to 8.63 per 100,000 person-years in the USA [9]. As ES usage is becoming increasingly popular, a parallel increase would be expected to occur in the rates of ES-related accidents and TBIs. There was an increasing trend of cases towards the end of the study period, which is likely related to the increased number of ESs and the loosening of the Covid-19 pandemic restrictions. We presume that the ES-related incident numbers in our city could have been higher without the Covid-19 restrictions limiting bar and nightclub visits. This was supported by the substantial increase in accidents in the latter months of the study during which the Covid-19 restrictions were relaxed. Lowering the maximum nighttime speed of the ESs in July 2021 did not seem to reduce the incidence of TBIs in our study. We did not access the incidence of other ways of micro-transportation during the study period. Previous studies have compared ES and bicycle accidents. Studies show that the estimated ED presentation rates per million miles traveled citywide were higher among e-scooter riders than cyclists (RR 3.76; 95\% CI, 3.08-4.59) and the ES riders are far less likely to wear helmets [3]. Trip purposes also vary, as bicycles are mainly used to commute to/from work and ESs are mainly used for social reasons and personal business $[3,10]$. Cyclists are more frequently injured on the road in incidents involving motor vehicles, and e-scooter riders sustain more injuries on sidewalks without the involvement of other road users. Compared to bicycle accidents, e-scooter accidents more commonly occur on weekends and in association with alcohol [10].

Based on previous research, ES-related accidents are more frequent when compared to cycling or pedestrian accidents 


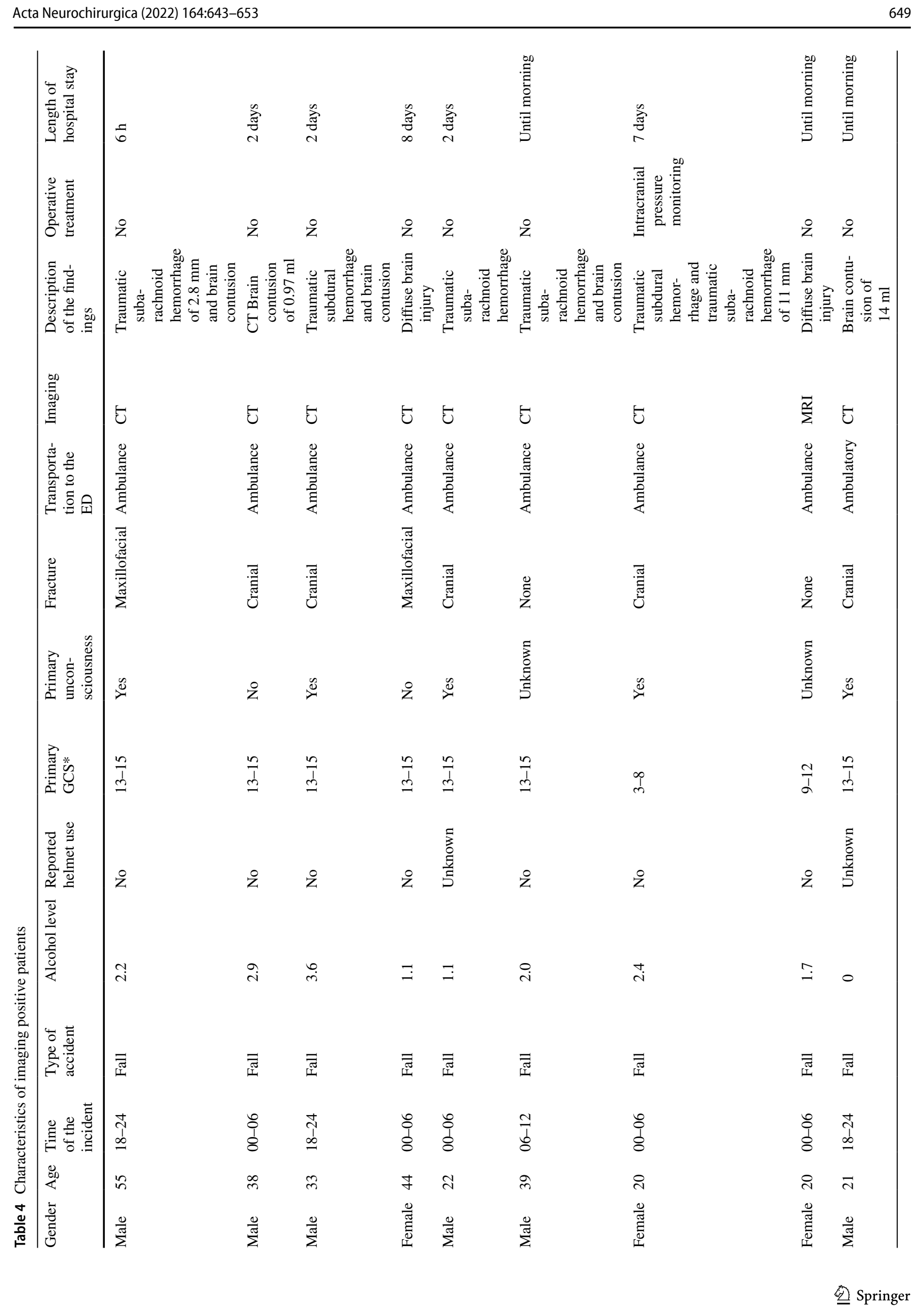




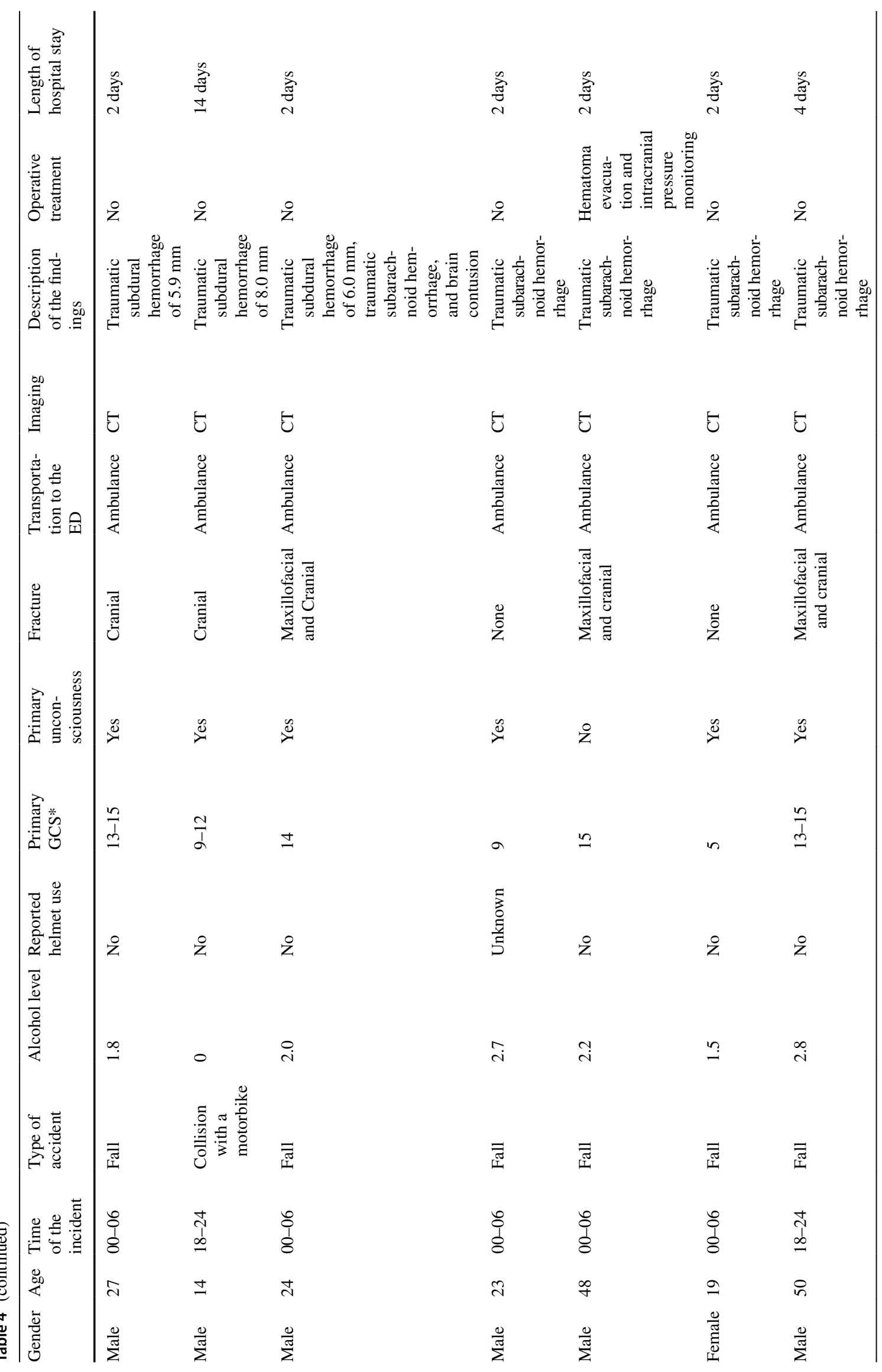


[31]. Similar to the findings of the present study, typical ES accidents occur in the summertime, late at night during the end of the week [26, 32]. Conditions such as cold weather, snow, and pandemic quarantine restrictions have been associated with lower rates of ES accidents [26, 32].

Electric scooter accidents are predominantly reported to involve only the scooter rider [2, 25, 26, 31]. In the current study, $92 \%$ of cases did not involve other road users, which indicates that most of the accidents result from handling errors. Furthermore, in $90 \%$ of the cases, there was a single person on board. Most ES-related injuries were related to alcohol intoxication in previous studies [7, 10, 20, 22, 31]. Our study showed a similar pattern, with $71 \%$ of the accidents involving alcohol intoxication. Noticeably, in alcohol-related accidents, the majority $(79 \%)$ of patients had a breath or blood alcohol content higher than 1.2\%o. In Finland, a law prohibits serving alcohol after $4 \mathrm{am}$, which forces bars and nightclubs to close and appears to demonstrate a significant contrast in the injury rates between 0-6 a.m. and 6-12 a.m. Alcohol intoxication is associated with an elevated risk for TBIs [13, 27]. A fivefold risk for TBI was observed in intoxicated patients in a previous study on ES-related injuries [32]. Another significant factor offering protection from TBIs is helmet use, which reduces the risk of serious head and facial injuries [21]. The helmet usage in ES-related accidents is strikingly low [1, 10, 15, 20, 30]. Supportive to our findings of reported helmet use (3.8\%), data from 16 studies ( $n=1656)$ showed that only $4.5 \%$ of cases of ES accidents involved helmet use [30]. The use of helmets might have been under-reported in our study, as the data on helmet use was missing in $33 \%$ of the cases.

\section{Limitations}

This study was limited by the retrospective study design. There may have been patients with ES-related TBIs without proper diagnose codes and/or description of the accident in the patient charts. We did not assess the long-term outcomes of the injuries. Primary imaging findings, GCS on arrival, and the need for operative management can be used for assessing the potential severity of the TBIs; however, using these markers alone does not justify any conclusions on how severe or mild a TBI will be in a follow-up [28]. This was a consecutive patient series treated in a single hospital during a 2.5 -year period. We did not assess the prevalence of TBIs related to other transportation methods. We do not have information on the rate of use and numbers of rentable ESs in our area.

\section{Conclusions}

Our results show a high rate of alcohol intoxication and lack of helmet use in patients with brain injuries related to electric scooters. The incidence increased towards the end of the 
study period. Imaging positive injuries were present in 18 patients. These results may be used to inform the public and legislators about the risk of traumatic brain injuries related to electric scooter accidents. We hypothesize that targeting the modifiable factors such as helmet use, preventing driving while intoxicated, and restricting nighttime use could decrease ES-related brain injuries.

Supplementary Information The online version contains supplementary material available at https://doi.org/10.1007/s00701-021-05098-2.

Acknowledgements We thank Dr. Jussi Posti for his help on this article.

Funding Open Access funding provided by University of Turku (UTU) including Turku University Central Hospital. Dr. Saarinen has received research funding from NuVasive Inc. not related to the present study. Funding was received from The Päivikki and Sakari Sohlberg Foundation and Vappu Uuspää Foundation for this study.

\section{Declarations}

Informed consent No patients were contacted. Therefore, no informed consent was required from the patients.

Open Access This article is licensed under a Creative Commons Attribution 4.0 International License, which permits use, sharing, adaptation, distribution and reproduction in any medium or format, as long as you give appropriate credit to the original author(s) and the source, provide a link to the Creative Commons licence, and indicate if changes were made. The images or other third party material in this article are included in the article's Creative Commons licence, unless indicated otherwise in a credit line to the material. If material is not included in the article's Creative Commons licence and your intended use is not permitted by statutory regulation or exceeds the permitted use, you will need to obtain permission directly from the copyright holder. To view a copy of this licence, visit http://creativecommons.org/licenses/by/4.0/.

\section{References}

1. Blomberg SNF, Rosenkrantz OCM, Lippert F, Christensen HC (2019) Injury from electric scooters in Copenhagen: a retrospective cohort study. BMJ open 9:e033988

2. Brownson AB, Fagan PV, Dickson S, Civil ID (2019) Electric scooter injuries at Auckland City Hospital. NZ Med J 132:62-72

3. Cicchino JB, Kulie PE, McCarthy ML (2021) Injuries related to electric scooter and bicycle use in a Washington, DC, emergency department. Traffic Inj Prev 22:401-406

4. Coronado VG, Xu L, Basavaraju S v, et al. Surveillance for traumatic brain injury-related deaths; United States, 1997-2007

5. Doser K, Poulsen I, Wuensch A, Norup A (2018) Psychological outcome after severe traumatic brain injury in adolescents and young adults: The chronic phase. Brain Inj 32:64-71

6. Eurostat. Revision of the European Standard Population-Report of Eurostat's task force

7. Farley KX, Aizpuru M, Wilson JM et al (2020) Estimated incidence of electric scooter injuries in the US from 2014 to 2019. JAMA Netw Open 3:e2014500-e2014500
8. Ishmael CR, Hsiue PP, Zoller SD et al (2020) An early look at operative orthopaedic injuries associated with electric scooter accidents: bringing high-energy trauma to a wider audience. JBJS 102:e18

9. Kappagantu A, Yaremchuk K, Tam S. Head and neck injuries and electronic scooter use in the United States. The Laryngoscope

10. Kleinertz H, Ntalos D, Hennes F et al (2021) Accident Mechanisms and Injury Patterns in E-Scooter Users: A Retrospective Analysis and Comparison with Cyclists. Dtsch Arztebl Int 118:117

11. Kosola S, Salminen P, Laine T (2009) Heading for a fallmoped and scooter accidents from 2002 to 2007. Scand J Surg 98:175-179

12. Maas AIR, Stocchetti N, Bullock R (2008) Moderate and severe traumatic brain injury in adults. The Lancet Neurol 7:728-741

13. Madan AK, Yu K, Beech DJ (1999) Alcohol and drug use in victims of life-threatening trauma. J Trauma Acute Care Surg 47:568-571

14. Majdan M, Plancikova D, Brazinova A et al (2016) Epidemiology of traumatic brain injuries in Europe: a cross-sectional analysis. The Lancet Public Health 1:e76-e83

15. Mayhew LJ, Bergin C (2019) Impact of e-scooter injuries on emergency department imaging. J Med Imaging Radiat Oncol 63:461-466

16. Mitchell G, Tsao H, Randell T et al (2019) Impact of electric scooters to a tertiary emergency department: 8-week review after implementation of a scooter share scheme. Emerg Med Australas 31:930-934

17. Moftakhar T, Wanzel M, Vojcsik A et al (2021) Incidence and severity of electric scooter related injuries after introduction of an urban rental programme in Vienna: a retrospective multicentre study. Arch Orthop Trauma Surg 141:1207-1213

18. Namiri NK, Lui H, Tangney $\mathrm{T}$ et al (2020) Electric scooter injuries and hospital admissions in the United States, 2014-2018. JAMA Surg 155:357-359

19. Official Statistics of Finland (OSF): Population structure. https:// pxnet2.stat.fi/PXWeb/pxweb/en/StatFin/

20. Oksanen E, Turunen A, Thorén H (2020) Assessment of Craniomaxillofacial injuries after electric scooter accidents in Turku, Finland, in 2019. J Oral Maxillofac Surg 78:2273-2278

21. Olivier J, Creighton P (2017) Bicycle injuries and helmet use: a systematic review and meta-analysis. Int J Epidemiol 46:278-292

22. Puzio TJ, Murphy PB, Gazzetta J et al (2020) The electric scooter: a surging new mode of transportation that comes with risk to riders. Traffic Inj Prev 21:175-178

23. Schlaff CD, Sack KD, Elliott R-J, Rosner MK (2019) Early experience with electric scooter injuries requiring neurosurgical evaluation in District of Columbia: a case series. World Neurosurg 132:202-207

24. Shichman I, Shaked O, Factor S et al (2021) Epidemiology of fractures sustained during electric scooter accidents: a retrospective review of 563 cases. JBJS 103:1125-1131

25. Shiffler K, Mancini K, Wilson M et al (2021) Intoxication is a significant risk factor for severe Craniomaxillofacial injuries in standing electric scooter accidents. J Oral Maxillofac Surg 79:1084-1090

26. Störmann P, Klug A, Nau C et al (2020) Characteristics and injury patterns in electric-scooter related accidents-a prospective twocenter report from Germany. J Clin Med 9:1569

27. Tagliaferri F, Compagnone C, Korsic M et al (2006) A systematic review of brain injury epidemiology in Europe. Acta Neurochir 148:255-268

28. Tenovuo O, Diaz-Arrastia R, Goldstein LE et al (2021) Assessing the severity of traumatic brain injury-time for a change? J Clin Med 10:148 
29. Tischler EH, Tsai SHL, Wolfert AJ, et al. Orthopedic fracture hospitalizations are revving up from E-Scooter related injuries. Journal of Clinical Orthopaedics and Trauma 2021; 101607

30. Toofany M, Mohsenian S, Shum LK, et al. Injury patterns and circumstances associated with electric scooter collisions: a scoping review. Injury prevention

31. Trivedi TK, Liu C, Antonio ALM et al (2019) Injuries associated with standing electric scooter use. JAMA Netw Open 2:e187381-e187381
32. Uluk D, Lindner T, Dahne M, et al. E-scooter incidents in Berlin: an evaluation of risk factors and injury patterns. Emergency medicine journal

Publisher's note Springer Nature remains neutral with regard to jurisdictional claims in published maps and institutional affiliations. 